\title{
Innovation business model of Big Data-- Taking Coca-Cola as an example
}

\author{
Liujieren, Xiaolin Li
}

School of Southwest University for Nationalities, Chengdu, 310000, China

\begin{abstract}
Keywords large data; business model innovation; Coca-Cola
\end{abstract}
Abstract. In the current era of big data, the general value chain of traditional supply-oriented business models are gradually dying out, the use of big data to establish or improve demand-driven business models are maturing. In this paper, Coca-Cola, for example, analysis of business model innovation method of big data era. By analyzing the value of Coca-Cola in the acquisition, and other aspects of innovation and value creation for Coca-Cola in the "big data" Time to explore innovative business model provides the entry point for a systematic analytical framework. On this basis, the Coca-Cola business innovation to adapt to the trend of development put forward some suggestions.

\section{Introduction}

"Big Data" is affecting the business ecosystem in a variety of ways and paths, which has become the basic background of enterprise business model innovation. From the point of view of management science, the application of using Big Data technology to support business analysis and decision-making has become a trend, complying with the force of a prairie fire is generally formed and the application boundary of Big Data can be expanded. The main point of this article is to analyze the business model innovation of Coca-Cola Company. While deepening the study of business model innovation, the paper also puts forward some suggestions for the retail business, which is about using business model innovation to meet new challenges in the Big Data environment and seizing more market opportunities.

\section{Features and characteristics of Big Data}

We live in an era of big data, except the consumer market, Big Data is increasingly becoming commonplace in various industries. Some organizations even innovate their entire business model, and create new services through the application of big data (McKinsey). The impact of Big Data is often reflected in the aspects of 3V- Volume, Velocity and Variety.

Three simple examples illustrate this phenomenon. Volume-Tesco has the data of 150,000 customers' shopping habits' going backwards 20 years ago. Velocity- micro-blog receives about 12 TB calling every day. Variety-more than 2 million photos are uploaded to Facebook every day. The $3 \mathrm{~V}$ subtly explains why we are experiencing a data explosion, which leads to an interesting development of consumer markets. More and more companies are using the data, and they can develop and access new insights to their customers and their behavior. A recent report by the World Economic Forum (WEF 2012) identified the use of Big Data for the purpose of economic development (e.g., health care, microfinance, education, agriculture). The same report also highlighted the importance of developing appropriate business model, which is to provide appropriate incentives to the private sector actors, and share and use data with them.

At present, there is no consistent understanding of the meaning of Big Data, Manyika ,etc, defines it as "data sets", which is using typical database software tools to capture, store, manage, and analyze data. Schroeck, etc, defines Big Data as using innovative forms of dealing with assets 
by "high capacity, high speed, and high information" to enhance insight and decision-making. After a general discussion of society, three areas of the Big Data are worth noting:

First of all, it is not only Big Data limited to data or volume, but also Big Data through a variety of different data types, the challenges of integration in different formats, velocity data, and with reference to the speed, processing and analysis of creating the data. Secondly, it refers to the Big Data as an "information asset", which means the value it lends to the organization. At last, it focuses on the new requirements for processing of this data with effective cost. Generally speaking, it means that using the integration and analysis of massive data to discover new knowledge is translated into the commercial advantages, which can bring great value, big profits and great development.

\section{Big Data Innovation of Business Models}

The role of Big Data to the enterprise basically includes: strengthening a series of enterprise behavior internal management from the inside to outside, improving the accounting business, strengthening basic detection and inspection on the function of products, and carrying out basic research, to improve the sales and expand customers, enhance customer service level, and achieve decision-making automation. Of course, some larger, mature companies have done quite well in this aspect. For example, Apple (40 years old) and Amazon (20 years old), both companies have formed a solid business model based on Big Data, and provide products and services to consumers by using Big Data. All come from the value proposition. Therefore, this paper highlights the business model based on three types of Big Data about value proposition and customer (such as: DAAS, IAAS, AAAS, etc.).

Firstly, we can call this business model "Data As A services" (DAAS) (Table 1). This business model is to focus on providing a method to dig their own unique insights for customers, or choose programs customers want, and what companies can do is to supply a lot of processing data for customers to solve the program. In this case, customers may be the solution programmer providers, and even the developers, who want to develop special applications to solve the problems customers worry about. To use data close to the original one tends to improve their products (that is, value proposition). In this kind of business model, summary data is obtained from the company's own customers or from external sources (major partners). As seen in DAAS's business model, the unique property of this business model is to create the market to sell a relatively low cost value proposition. However, the most important thing is to generate trust among all customers, which makes it spin off any sensitive customer details. For example, Twitter allows Big Data customers to create any personal information about their own unique value proposition. Data with problems is processed by the firm's key resources (or the main partners), and the rest of this business model is to ensure that cleaned up customers can get the data to enhance its value proposition. Because in this case, the data is only valuable thing, which can provide support mechanisms for customers to create other value propositions and in some cases, source of income is usually relatively low, and, perhaps, even it is free to use this business model to search for the open web site data, such as datasf.org, and some commercial vendors, such as GNIP and even Twitter. 
Table 1 "Data As A services" (DAAS)

\begin{tabular}{|c|c|c|c|c|c|}
\hline \multirow{2}{*}{$\begin{array}{c}\text { Main Partners: } \\
\text { Third-party } \\
\text { Data Source } \\
\text { Eg: Online Portal } \\
\text { Service provider } \\
\text { or Developer }\end{array}$} & $\begin{array}{l}\text { Main Activity: } \\
\text { Visualization } \\
\text { Marketing \&Sales } \\
\text { Data Process }\end{array}$ & \multirow{2}{*}{\multicolumn{2}{|c|}{$\begin{array}{l}\text { Value } \\
\text { Proposition: } \\
\text { Professional } \\
\text { data to } \\
\text { establish } \\
\text { customer's own } \\
\text { solutions }\end{array}$}} & $\begin{array}{l}\text { Customer } \\
\text { Relationship: } \\
\text { Self-service } \\
\text { Online service }\end{array}$ & \multirow{2}{*}{$\begin{array}{l}\text { Customer } \\
\text { Group: } \\
\text { Business } \\
\text { Solutions } \\
\text { Dealer } \\
\text { Developer }\end{array}$} \\
\hline & $\begin{array}{l}\text { Main source: } \\
\text { Data } \\
\text { Brand } \\
\text { Market } \\
\text { Professional data } \\
\text { knowledge and } \\
\text { relationships }\end{array}$ & & & $\begin{array}{l}\text { Channel: } \\
\text { Subscribe through } \\
\text { the mail } \\
\text { Dealer }\end{array}$ & \\
\hline $\begin{array}{l}\text { Cost framework: } \\
\text { Market } \\
\text { Sales } \\
\text { Internet } \\
\text { Process } \\
\text { Third-party sales li }\end{array}$ & & Data & \multicolumn{3}{|c|}{$\begin{array}{l}\text { Revenue Stream } \\
\text { Free subscription fee }\end{array}$} \\
\hline
\end{tabular}

Second Big Data business model, the so-called "information as a service" (IAAS) (Table 2), focuses on providing the analytical insights of data on the basis of processing. In this case, more of the client's work to be done is the future with their own conclusions, or even the idea of certain information based on the "sale". In addition, IAAS's customers do not want to have no resources to process and analyze data. On the contrary, they are willing to exchange the value of analysis with the parties they trust. Unlike the DAAS business model, which is about gathering and processing of large amounts of data transmission, and create their own value proposition for customers, IAAS business model is all about transforming data into information, and customers need to pay equivalents for the information. To do this, key activities must include analysis and data visualization, as well as research may enhance the analysis of data. Value proposition may also be targeted at specific customer groups. For example, Audi, BMW, and Benz, will sell location information to companies for their own navigation applications. To do this, it needs to collect, gather, and eventually clear the data to make it become an information program and a visual map (that isinformation), which can be the form sold to customers. From a consumer point of view, many health-trackcompanies, such as sales products of Fit Bit, focus on providing value proposition based on tracking consumer behavior analysis. Here like FitBit collects, gathers and transfer the data into information for consumers, which can be used for our own personal analysis. 
Table 2 "Information As A services" (IAAS)

\begin{tabular}{|c|c|c|c|c|}
\hline \multirow[t]{2}{*}{$\begin{array}{l}\text { Main Partners: } \\
\text { Third-party Data } \\
\text { Source } \\
\text { Analysis Tool } \\
\text { Solution Provider }\end{array}$} & $\begin{array}{l}\text { Main Activity: } \\
\text { Data Gather } \\
\text { Clear } \\
\text { Marketing \&Sales } \\
\text { Data analysis and } \\
\text { visualization }\end{array}$ & \multirow{2}{*}{$\begin{array}{l}\text { Value } \\
\text { Proposition: } \\
\text { Information } \\
\text { services make } \\
\text { better } \\
\text { conclusions } \\
\text { Accuracy } \\
\text { Real } \\
\text { Convenient } \\
\text { One and only }\end{array}$} & $\begin{array}{l}\text { Customer } \\
\text { Relationship: } \\
\text { Self-service } \\
\text { Online service } \\
\text { Direct } \\
\text { communication }\end{array}$ & \multirow[t]{2}{*}{$\begin{array}{l}\text { Customer } \\
\text { Group: } \\
\text { Business } \\
\text { Solutions } \\
\text { Dealer } \\
\text { Consumers }\end{array}$} \\
\hline & $\begin{array}{l}\text { Main source: } \\
\text { Data } \\
\text { Brand } \\
\text { Market } \\
\text { Professional data } \\
\text { analysis }\end{array}$ & & $\begin{array}{l}\text { Channel } \\
\text { Direct selling } \\
\text { Dealer } \\
\text { In-app } \\
\text { Online service }\end{array}$ & \\
\hline \multicolumn{2}{|c|}{$\begin{array}{l}\text { Cost framework: } \\
\text { Market } \\
\text { Sales } \\
\text { Internet } \\
\text { Third-party sales license } \\
\text { Data Analysis \& Visualization }\end{array}$} & \multicolumn{2}{|c|}{$\begin{array}{l}\text { Revenue stream: } \\
\text { Advertising fee } \\
\text { Subscribe }\end{array}$} & \\
\hline
\end{tabular}

The third Big Data business model is called "answer as a service" (AAAS) (Table 3). It focuses on specific issues, which provides high-level answers, rather than simply come up with an answer to deal with the used information. AAAS customers often need answers to determine the specific direction. In fact, in this case, the customer may be willing to give the right value proposition, which is spontaneous "buy" decision. This business model is the top of the Pyramid. As for big data, the key of this business model is to taking into account the company's ability to create the true and real value for customers, and in turn the customer will increase the amount of physical exchange value. In this case, an interesting example is Mint- personal finance service (online APP).Mint makes it very easy for any person to provide some basic information, such as bank details. Therefore, the mint will track, analyze and visualize information consumers generate. But if the answers begin to play a role, or consumers provide credit card information, the mint will not only use existing transaction information for those credit cards, the service also sells information provided to other credit card companies, in return for doing advertising credit ability cards and better interest rate (that is, the answer). However, customers' information is often contrary to the notion that some companies sell their credit card information. In this case, there is true or false, and the answer is returned to the consumer by the desired value exchange. Similarly, Baidu's photo service will identify people, places, and situation as well as the latest personal information byphotos. The key of this business model is the value proposition, in which customers are doing their own research or planning their own photos. Therefore, this business model is to use more ways to carry out the value exchange. 
Table 3 "AnswerAs A services" (AAAS)

\begin{tabular}{|c|c|c|c|c|}
\hline \multirow[t]{2}{*}{$\begin{array}{l}\text { Main Partners: } \\
\text { Third-party Data } \\
\text { Analysis Tool } \\
\text { Solution Provider } \\
\text { Online service }\end{array}$} & $\begin{array}{l}\text { Main Activity: } \\
\text { Data Gather } \\
\text { Clear } \\
\text { Analysis } \\
\text { Market } \\
\text { Business Development }\end{array}$ & \multirow{2}{*}{$\begin{array}{l}\text { Value } \\
\text { Proposition: } \\
\text { AAAS } \\
\text { Dynamic } \\
\text { Quotation } \\
\text { Real } \\
\text { Timely } \\
\text { Convenient } \\
\text { Reliability }\end{array}$} & $\begin{array}{l}\text { Customer } \\
\text { Relationship: } \\
\text { Interaction } \\
\text { Reserve } \\
\text { Direct } \\
\text { communication } \\
\end{array}$ & $\begin{array}{l}\text { Customer } \\
\text { Segmentation: } \\
\text { Consumers } \\
\text { Third-party } \\
\text { advertisers }\end{array}$ \\
\hline & $\begin{array}{l}\text { Main source: } \\
\text { Brand } \\
\text { Potential customers } \\
\text { Market knowledge }\end{array}$ & & $\begin{array}{l}\text { Channel } \\
\text { Direct selling } \\
\text { Dealer } \\
\text { In-app } \\
\text { Online service }\end{array}$ & $\begin{array}{c}\text { Enterprise } \\
\text { Decision maker }\end{array}$ \\
\hline \multicolumn{2}{|c|}{$\begin{array}{l}\text { Cost framework: } \\
\text { Market } \\
\text { Sales } \\
\text { Internet } \\
\text { Third-party sales license } \\
\text { Online service }\end{array}$} & \multicolumn{3}{|c|}{$\begin{array}{l}\text { Profit model: } \\
\text { Advertising fee equivalent exchange } \\
\text { Product sales }\end{array}$} \\
\hline
\end{tabular}

From three kinds of business model innovation above, the Big Data drives the innovation of business models, which is the way to achieve business model innovation.

\section{Coca-Cola - Business Model Innovation Case of Big Data}

Coca-Cola was founded in 1892, which is famous for its production of sweet carbonated drinks. Today, nearly 120 years later, Coca-Cola is still strong, which owns to its continuous innovation. From the point view of business model innovation affected by Big Data, the core part can't be separated from the value proposition.

Coca-Cola proposes "everywhere" as the direction of innovation, and opens a new business model with "coke is it "as the theme.

As the world's largest non-alcoholic beverage company, Coca-Cola produces PB data from a variety of sources: data of multi-channel retail, customer personal data of loyalty program, data of social media, data of supply chain, data of competitors, data of sales and shipment bottling partners, data of trading and sales, etc. Coca-Cola collects a large number of data, use these data to access and create value, and finally realize the value proposition (Figure 1). 


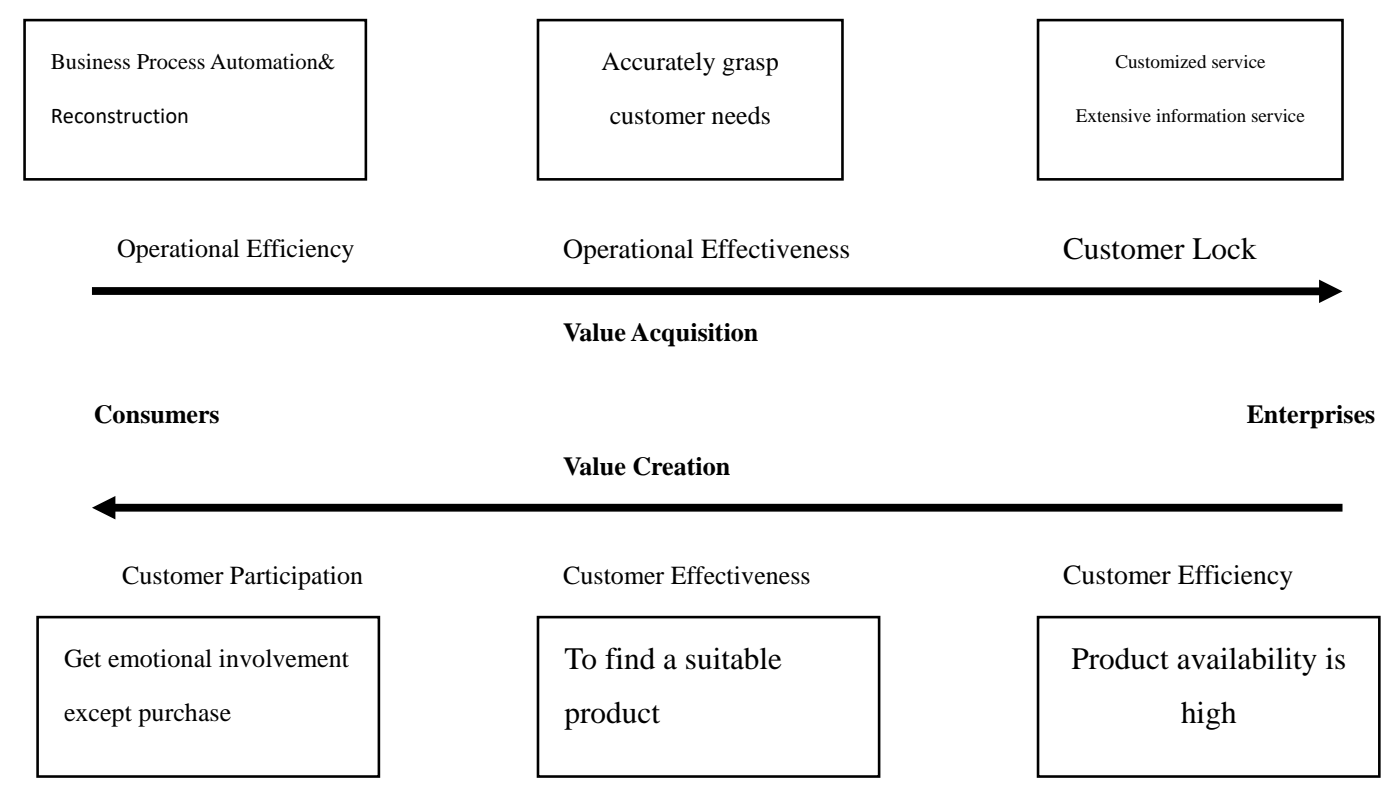

Fig. 1 Value Proposition

Chief Big Data insight ESutter Sezer explains that many companies avoid Big Data, because they do not know how to make use of its strategic value. However, this can be achieved simply by rethinking your business model, and achieve it with right data sources and pulling all numbers into a position. Coca-Cola takes Big Data strategy. They change Coca-Cola by setting a large number of existing data. At the same time, the acceptance of big data technology can create financial transaction activity sharing service center and human resources service center for Coca-Cola. Data is transferred from decentralization to centralization by sharing platform and concentration in the whole organization.

\subsection{Analysis of Business Model Innovation based on Big Data}

1) Value discovery-indirect effects. Coca-Cola has nearly 70 million followers of Facebook. Big data enables Coca-Cola to connect to the preferences of these followers, and can promote the brand. Coca-Cola also uses sales data points to build customer files from like Wal-Mart (Wal-Mart alone is responsible for $\$ 4$ billion Coca-Cola sales annually), creates reports from iPad in the whole company, makes it into the supply chain by collaborative plan, forecastand replenish by using all data.

2) Value Discovery-direct impact. Orange has a short peak growing season of three months, and Coca-Cola can use it to produce a consistent taste of orange juice all the year round. Coca-Cola has developed an algorithm, known as the "black book mode ", which combines different data sets, such as satellite images, weather date, cost pressures, and consumer preferences of different regions. It consists of About 600 different countless orange flavors with data and many other variables, such as acidity or sweetness rate, which tells you how Coca-Cola blends the orange juice to create a consistent taste and enhance the pulp content.

3) Value Creation-indirect impact. Coca-Cola is provided in 206 countries and privacy is a major issue of Coca-Cola. Coca-Cola uses the last 10 years of data governance to ensure respect for the sensitivity of different social and cultural. In a blog of Computer Weekly, Fithen Katherine, Coca-Cola's Chief Privacy Officer, explained: "In the United States, use of customers' information is considered illegal. In other cultures, it is considered to be tracking. To use GPS data is not to inquire about the privacy of our customers, but to know the specific distribution of customers, so as to carry out specific advertising. 
4) Value creation-direct impact. Big Data is used throughout the Coca-Cola's other departments, such as classification management, shopper market or supply chain. Using of a large number of data helps to make more and better key decisions. Coca-Cola has developed an advanced enterprise data warehouse, which can produce all the multi-channel retail information, so that it can response on a single view of changing market quickly and accurately. Coca-Cola achieves its ultimate goal through a series of master data management process to standardize all data, which is to help Coca-Cola effectively to promote sales and enhance consumers' using experience.

It is clear that Coca-Cola is far ahead of using Big Data to improve their organization and products, increase revenue and reduce costs. It is known that Coca-Cola can use $46 \%$ of its staff to analyze data, and at the same time reduce overtime costs, but the value created is that the orange juice tastes exactly the same in four seasons in the world of any place. Coca-Cola makes use of the "black book" algorithm to do the job correctly.

\subsection{Summary}

Coca-Cola has experienced a hundred years of development, and has made a good use of Big Data to build a global sales business model. Fierce competition in the retail industry results in the explosive growth of the industry data, in which the traditional information processing system is also facing big challenges. For entire industry, Big Data is throughout the future of the production and management of retail industry in every aspect, which plays a unique and significant role, contributes to creating next generation sales system for the retail industry successfully, responses effectively to environmental stress, growing scarcity of resources and other issues, and achieves green and sustainable development. Therefore, Coca-Cola, as a leader in the retail industry, has taken exploration pace. The successful operation of Big Data can bring new data operation and maintenance mode, form a new way and consumption pattern, and give users a new experience. Although Coca-Cola has a failure of innovation in history, but in order to break the traditional business model before, it provide "everywhere" support for the production operation and management of enterprises from the perspective of data analysis and management.

\section{Conclusion and Discussion}

The paper chooses the case of Coca-Cola to study based on the concept model of business model innovation driven by Big Data, and the main conclusions are as follows:

First of all, by analyzing the case that Coca-Cola use Big Data to achieve business model innovation, the paper finds Big Data has direct and indirect influence on the gaining competitive advantage and innovation process of enterprise business models. Big Data, as a new technology application, directly affects the enterprises enhancing environment insights, discovers customer value, improve enterprise internal operation, innovation product services and profit model, etc. to achieve business model innovation in all aspects.

Secondly, for enterprises, it often starts from value discovery and value creation, gradually accumulates Big Data applications, basic knowledge and experience of business model innovation, and finally realizes the value proposition, which forms thorough business model innovation.

Although Big Data has been applied in all walks of life, such as the case of Coca- Cola is the leader in the application of Big Data in the industry. But generally speaking, the application of Big Data is still in exploratory and pilot phase, especially for the traditional industries, and to carry out transformation of business models, has to face the following challenges:

(1). Training and Selection of Leaders

Coca-Cola succeeds in the era of Big Data not only for that they have more and better data, but also for that they have set clear goals for leadership team, define success look, and ask right 
questions. Coca-Cola's reform and transformation has also experienced failure, the main reason is that the direction of leadership is not clear. The existence of Big Data provides better suggestion for management team, leads clear leadership direction, makes it easy to understand how the market is developing and think creatively, and puts forward truly innovative products. So, each enterprise should make good use of Big Data to carry out the transformation of business model. First of all it is essential to have leaders, who have a clear direction of development, and to persuade people to accept the new business model, and strive to achieve it. At the same time, it can effectively deals with the relationship between customers, employees, shareholders and other stakeholders.

(2). Talents Discovery

With data easy to be got, the supplementary data becomes more valuable. In the era of Big Data, the most critical factor is the data scientists and other professionals who are good at working with a lot of information. Statistical data is important, but many of key techniques using Big Data are rarely taught in traditional statistical courses. Perhaps what is more important is the ability to clean up and organize big data sets. As new types of data are rarely available in theory, visualization tools and techniques have to be added. So a new generation of computer scientists is responsible for work of data very large data collation and collection. To achieve successful transition for enterprises in the era of Big Data, scientists can use the data of best choice to help leaders to develop their own challenges, and select the way for their business transformation. So, in the era of Big Data, the people, who can deal with and collect data, are demanded. ("data scientists: twenty-first century's most sexy job", H. Davenport and D.J. Patil Thomas.)

\section{(3). Clear Corporate Culture}

When an enterprise needs to carry out business transformation, the first question is: "what is the business needs?" or "whether it can meet the expectations of enterprises after the business transformation?". Many enterprises find that this is not the desired transformation model after the collection and processing of data. Therefore, before making use of the Big Data, it is necessary to take into account whether the data is required by the enterprise itself or not, and whether the enterprise can make use of these data by integrating it into the enterprise culture. Because many companies only catch up with the tide of Big Data blindly, and forget the business culture of enterprise itself. So, when making use of Big Data to carry out the transformation, firstly it is essential to make their own culture clear.

The conclusion is clear: decisions driven by data are often better ones. We can’t say that all companies have to use Big Data to transform the business model. But the data will tell the business executives, what the best direction of development is.

\section{References}

[1] Jay Moye,Creating a Win-Win: Inside Coke’s New Startup Model, Oct 16, 2014.

[2] Mark van Rijmenam ,How Coca-Cola Takes a Refreshing Approach to Big Data, July 19, 2013.

[3] Hufeng Peng, Manyu Huang. Retail Business Model Innovation and Path Analysis Based on New Technological Environment. Macroeconomic Research, 2014, No. 2

[4] Dhadge Anjali R., GawaliSunita S., Gore Pooja R., Prof. Ms.SonaliPatil, An Recommendation Based Process Modelling Support: Method And User Experience, International Engineering Research Journal (IERJ) Volume 1 Issue 8 Page 609-612, 2015, ISSN 2395-1621.

[5] Philipp Max Hartmann, Mohamed Zaki, NielsFeldmann and Andy Neely, Big Data for Big Business? A Taxonomy of Data-driven Business Models used by Start-up Firms.

[6] Justin, Exploring Big Data Business Models \& The Winning Value Propositions Behind Them, 


\section{August 21st 2015}

[7] Wei Li, Xiaotao Xi. The Value, Foundation and Directions of the Studies on Marketing Innovation in the Big Data Era. Technology Management Research, 2014, No. 18.

[8] Min Luo, Liangyu Li. Business model innovation under Internet era: Value Creation Perspective. China Industrial Economy. 2015, No. 1.

[9] Dan Liu, Jiantong Cao, Lu Wang. Innovation Research of business models based on large data. Contemporary Economic Management, 2014, Vol. 36, No. 6.

[10] Information on: www.intel.com/retail.

[11] Unbottled Staff,fountaionof data: coke freestyle dispense insights along with beverages,Oct 31, 2014

[12] David Butler, from satrtup to scaleup: the next wave of innovation, Aug 6, 2013.

[13] Wenlian Li, Jianming Xia. Business model innovation Based on" big data ". China Industrial Economy, 2013, no5.

[14] Andrew McAfee, Erik Brynjolfsson, Big Data: The Management Revolution,Oct 12.2012

[15]James Manyika, Michael Chui, Brad Brown, Jacques Bughin, Richard Dobbs, Charles Roxburgh, Angela Hung Byers, Big data: The next frontier for innovation, competition, and productivity, McKinsey Global Institute,May 2011 